\title{
Alteration in propagating colonic contractions by dairy proteins in isolated rat large intestine
}

\author{
J. E. Dalziel, ${ }^{1,2 *}$ J. S. Peters, ${ }^{1}$ K. E. Dunstan, ${ }^{1}$ C. M. McKenzie, ${ }^{3}$ N. J. Spencer, ${ }^{4}$ N. W. Haggarty, ${ }^{5}$ \\ and N. C. Roy ${ }^{1,2,6}$ \\ ${ }^{1}$ Food Nutrition and Health Team, AgResearch, Palmerston North 4474, New Zealand \\ ${ }^{2}$ Riddet Institute, Massey University, Palmerston North 4474, New Zealand \\ ${ }^{3}$ Bioinformatics and Statistics, AgResearch, Grasslands Research Centre, Palmerston North 4474, New Zealand \\ ${ }^{4}$ College of Medicine and Public Health, Flinders University, School of Medicine, Adelaide 5001, South Australia, Australia \\ ${ }^{5}$ Fonterra Co-Operative Group, Palmerston North 4474, New Zealand \\ ${ }^{6}$ High-Value Nutrition, National Science Challenge, Liggins Institute, University of Auckland 1023, New Zealand
}

\section{ABSTRACT}

Gastrointestinal conditions in which the transit of contents is altered may benefit from nutritional approaches to influencing health outcomes. Milk proteins modulate the transit of contents along different regions, suggesting that they have varying effects on neuromuscular function to alter gastrointestinal motility. We tested the hypothesis that bovine whey and casein milk protein hydrolysates could have direct modulatory effects on colonic motility patterns in isolated rat large intestine. Casein protein hydrolysate $(\mathrm{CPH})$, whey protein concentrate (WPC), whey protein hydrolysate $(\mathrm{WPH})$, and a milk protein hydrolysate $(\mathrm{MPH}$; a hydrolyzed blend of $60 \%$ whey to $40 \%$ casein) were compared for their effects on spontaneous contractile waves. These contractions propagate along the length of the isolated intact large intestine $(22 \mathrm{~cm})$ between the proximal colon and rectum and were detected by measuring activity at 4 locations. Milk proteins were perfused through the tissue bath, and differences in contraction amplitude and frequency were quantified relative to pretreatment controls. Propagation frequency was decreased by $\mathrm{CPH}$, increased by $\mathrm{MPH}$, and unaffected by intact whey proteins. The reduced motility with $\mathrm{CPH}$ and increased motility with $\mathrm{MPH}$ indicate a direct action of these milk proteins on colon tissue and provide evidence for differential modulation by hydrolysate type. These findings mirror actions on lower gastrointestinal transit reported in vivo, with the exception of WPH, suggesting that other factors are required.

Key words: gastrointestinal, casein, whey, hydrolysate

Received April 12, 2019.

Accepted July 19, 2019.

*Corresponding author: julie.dalziel@agresearch.co.nz

\section{INTRODUCTION}

Bovine milk proteins are of benefit to human health as a nutritious protein source and through their ability to alter physiological function by the peptides they release (Korhonen, 2009). As a major component of a variety of food products, including pediatric formulations and sports supplements, hydrolyzed forms of casein and whey provide a more easily digestible protein with a rich source of peptides. Milk-derived peptides have a wide range of biological actions, such as antihypertensive, antioxidant, and immunomodulatory actions, and improved metabolic health (McGregor and Poppitt, 2013). They can also alter the functional attributes of the digestive tract itself, such as gastrointestinal (GI) motility and permeability (Jahan-Mihan et al., 2011). Understanding these actions will allow milk protein hydrolysates to be recognized as potential functional food ingredients. Because milk protein hydrolysates are already used as functional food ingredients in a range of general foods and for specialty clinical nutrition purposes, this knowledge is widely applicable (Abd ElSalam and El-Shibiny, 2017).

Peptides released from casein during digestion and those present in casein hydrolysates can act on receptors in the GI tract to alter the functional properties of the mucosa (Boutrou et al., 2013). For example, in vitro studies have indicated that $\beta$-casomorphin peptides can cross an epithelial cell layer (Iwan et al., 2008) and $\beta$-casomorphin 7 can alter permeability (Jarmołowska et al., 2013). As well, $\beta$-casomorphin 5 binds preferentially to $\mathrm{mu}$ opioid receptors (Schmidt et al., 1991), increases colonic motility in isolated rat large intestine (Dalziel et al., 2014), and slows GI transit in vivo (Daniel et al., 1990). The opioid agonist activity of hydrolyzed whey has been demonstrated in rat distal colon (Dalziel et al., 2016). To optimize the benefits of milk protein hydrolysates for human health, supporting evidence on their modes of action is required. Because hydrolysates 
are partially predigested forms of milk protein, they are further broken down before reaching the intestinal regions and are therefore more bioavailable than their intact counterparts. Milk protein hydrolysates have a long history of use in infant formula, originally because of their reduced allergenicity. The predigested state of partially hydrolyzed proteins may also improve infants' digestion of proteins. Infant formula intolerance can occur because the activity and secretion of pepsin at birth is limited and protein digestion is inefficient (Mason, 1962; Bourlieu et al., 2014). This maturation effect means that milk proteins and peptides in infant formula are more likely to reach the large intestine with incomplete proteolysis. Thus, ex vivo tissue might be a particularly applicable model for infant colonic motility.

Digesta are propelled along the GI tract by a coordinated series of contractile waves that involve the contraction and relaxation of smooth muscle (Spencer et al., 2016). Because this process is controlled by the enteric nervous system, it operates independently of the central nervous system. Recently, fecal output was shown to increase for rats fed a diet containing whey protein hydrolysate (WPH) or milk protein hydroylsate (MPH; a mixed whey:casein blend) compared with those fed casein protein hydrolysate $(\mathbf{C P H}$; Dalziel et al., 2017b). We therefore predicted that whey protein concentrate (WPC) and MPH would increase colonic motility compared with $\mathrm{CPH}$ in ex vivo large intestine. Likewise, because WPH increased fecal output compared with WPC in vivo, we predicted that WPH would also increase motility compared with WPC ex vivo.

The aim of this research was to determine the changes in GI motility patterns that underlie the propulsion of luminal contents due to the action of milk proteins. We investigated the actions of WPC, WPH, and MPH and compared them with $\mathrm{CPH}$ in isolated rat large intestine. The large intestine can be studied ex vivo as a section of isolated tissue that spontaneously generates propagating contractile waves. This GI motility reflects activity patterns important for mixing, stool formation, and the transit of contents through the lower GI tract in vivo, which can be measured as fecal output. Isolated tissue models of GI activity that reflect in vivo function would also assist future mechanistic studies. Furthermore, ex vivo tissue models that reflect in vivo physiological outcomes may provide useful predictive tools. This is especially relevant for infant digestion, where clinical studies are limited (Bourlieu et al., 2014).

Because sodium caseinate (intact casein) is readily digestible, it is highly unlikely that any would survive beyond the stomach to reach the large intestine (especially in adults), so it was not included in this study. We hypothesized that the hydrolyzed milk proteins could exert a direct modulatory action on colonic function to modify GI motility ex vivo, and this would support the previously reported effects on the lower GI tract of rats in vivo. In contrast, a lack of correlation with in vivo gut motility effects would suggest an indirect mechanism that requires in vivo factors, such as modulatory neural inputs or further digestion. We used rat intestine because rats' colonic motility patterns are well characterized, and rats are considered a model species for understanding human GI motility. Furthermore, the identification of specific milk peptides capable of modulating motility with potential actions to improve transit and relieve constipation was possible in this ex vivo model.

\section{MATERIALS AND METHODS}

\section{Animals}

This study was carried out in accordance with the recommendations of the New Zealand Animal Welfare Act 1999. The protocol was approved by the AgResearch Limited (Grasslands) Animal Ethics Committee (Ethics Approval No.: AE13449). Male adult Sprague Dawley rats, 3 to 6 mo of age and weighing 250 to $400 \mathrm{~g}$, were obtained from AgResearch Ruakura (Hamilton, New Zealand). The rats were housed under a 12-h light/dark cycle and fed Sharpe's Diet 86 (Sharpe's Stockfeeds Ltd., Carterton, New Zealand). Food and water were available ad libitum.

\section{Dietary Protein}

Milk proteins were provided by Fonterra Co-operative Group (Palmerston North, New Zealand), processed from bulk milk sourced from mixed herds. The following 4 milk protein products were studied: WPC (lactic whey protein concentrate WPC7009; 80\% protein wt/ wt), CPH (partially hydrolyzed casein MPH948; degree of hydrolysis $7.6 \%$; $94 \%$ protein wt/wt); WPH (partially hydrolyzed whey WPH917; degree of hydrolysis 7.0\%; $90 \%$ protein wt/wt); and MPH (partially hydrolyzed blend of 60:40 whey:casein MPH942; degree of hydrolysis $12-17 \%$; $85 \%$ protein wt/wt). Note that MPH has previously been referred to as a "hydrolyzed blend" (Dalziel et al., 2017b). The protein powders were dissolved in Krebs buffer at $1 \mathrm{mg} / \mathrm{mL}$ (concentration estimated to reach the infant lower GI tract) and perfused into the tissue bath at a rate of $20 \mathrm{~mL} / \mathrm{min}$. See Table 1 for peptide profiles of the CPH and WPH.

\section{Whole Large Intestine}

The protocol for recording motility in isolated intact whole large intestine has recently been described (Dal- 
Table 1 . Whey and casein hydrolysate peptide profiles (average) ${ }^{1}$

\begin{tabular}{lcc}
\hline Mass range (Da) & $\begin{array}{c}\text { Casein protein } \\
\text { hydrolysate }\end{array}$ & $\begin{array}{c}\text { Whey protein } \\
\text { hydrolysate }\end{array}$ \\
\hline$>20,000$ & 7 & 44 \\
$5,000-20,000$ & 18 & 17 \\
$1,500-5,000$ & 27 & 16 \\
$1,000-1,500$ & 11 & 6 \\
$500-1,000$ & 16 & 8 \\
$<500$ & 21 & 9 \\
\hline
\end{tabular}

${ }^{1}$ Molecular weights for hydrolysates were determined by size exclusion chromatography.

ziel et al., 2014, 2015, 2017a). Briefly, the entire large intestine was removed following isoflurane anesthesia and immediately placed in a beaker containing oxygenated $\left(95 \% \mathrm{O}_{2}, 5 \% \mathrm{CO}_{2}\right)$ Krebs solution. The animal was then euthanized with an intracardiac injection of a lethal dose of sodium pentobarbital $(70 \mathrm{mg} / 100 \mathrm{~g})$. The colon was gently flushed to expel fecal pellets, and the entire tissue was then mounted in an organ bath (approximately $350 \mathrm{~mL}$ capacity). A stainless steel rod (35 $\mathrm{cm}$ in length and $2 \mathrm{~mm}$ in diameter) was inserted through the lumen of the colon, which was then perfused at $20 \mathrm{~mL} / \mathrm{min}$ with Krebs buffer at $35 \pm 1^{\circ} \mathrm{C}$. The lumen was also perfused with Krebs buffer at 1.5 $\mathrm{mL} / \mathrm{min}$, which was pumped aborally using a constant flow pump, because this provided the pressure required to record consistent propagating contractions. Changes in circular muscle tension were recorded from 4 sites simultaneously along the length of the large intestine, which was stabilized by an internally placed metal rod. Four custom-made metal hooks - anchored $3 \mathrm{~cm}$ from both the oral and anal ends of the preparation and evenly spaced at approximately $4 \mathrm{~cm}$ intervals - were connected via silk thread to force transducers, and contractions were measured after applying $2 \mathrm{~g}$ of tension. Muscle contraction data were recorded using isometric force transducers (MLT0201) connected to an 8-channel bridge amplifier, integrated using PowerLab 8/35 hardware and acquired and analyzed using LabChart 8 software. All recording equipment hardware and software were from ADInstruments Pty Ltd. (Bella Vista, NSW, Australia).

Definition Criteria for Motility Patterns. Contractile patterns were recorded from the circular muscle layer at 4 locations simultaneously along the length of the large intestine (proximal colon, mid-colon, distal colon, and rectum), before and after the addition of treatment conditions. Motility patterns were quantified with respect to changes in the frequency and amplitude of synchronous and nonsynchronous phasic contractions, and contractions that occurred only in the proximal colon. "Synchronous contractions" were those that were temporally synchronized at least 3 of 4 adjacent recording sites. This definition would, in theory, include contractions that were anterograde (anally migrating), retrograde (orally migrating), or bidirectional (i.e., starting in the mid-colon and propagating both in an anterograde and retrograde direction). Nonsynchronous contractions were those that occurred in the proximal colon and were not temporally coordinated with more distal recording sites.

Experimental Design. Contraction frequency and amplitude were measured during a 30-min control recording and compared with findings over $30 \mathrm{~min}$ and 30 to $60 \mathrm{~min}$ of exposure to treatments, and after 30 min of washout. Because these synchronous and nonsynchronous contractions were likely play a major role for the coordinated propulsion of luminal contents, we compared them statistically between pretreatment control and treatment groups. All 4 milk protein treatments were applied to the serosal side of each preparation, via the perfusion tube supplying the bath. Thus, these substances would need to be absorbed and reach the peripheral circulation to be capable of modulating colonic motility.

\section{Statistical Analysis}

Results are expressed as the mean $( \pm$ SEM) of 5 or 6 tissue preparations. Data on the effects of the milk proteins were normalized within each experiment to account for variability between animals. Only 1 milk protein was applied to each tissue preparation. Ratios for each time point were calculated by dividing the tension or frequency during treatment by the initial time point before addition of the treatment from the last 30 min of the 1-h control recording, and the data were analyzed at the time point of maximal effect (60 min). We used ANOVA for the response variable (propagating tension) to compare the effects of treatment (4 milk proteins) and transducer (4 locations), and for treatment for the response variables (frequency and tension of propagating and nonpropagating contractions). The assumptions for ANOVA were met using log ratios. We used Fisher's least significant differences post hoc test to compare treatments. All analyses were carried out using GenStat version 18 (VSN International Ltd., Hemel Hempstead, UK).

\section{RESULTS AND DISCUSSION}

Mechanical recordings from the circular muscle layer revealed ongoing contractions at a frequency of $6.3 \pm$ 0.5 every $30 \mathrm{~min}(\mathrm{n}=22)$ that were defined as synchronous contractions and propagated along the length of the large intestine during the pretreatment control period. This pattern of contractile activity was similar 
to that previously reported for rat colon (Costa et al., 2013; Dalziel et al., 2014, 2015, 2017a). The maximal effects of the milk proteins on colonic motility were observed $30 \mathrm{~min}$ after application, over a further $30 \mathrm{~min}$ (30-60 min) used as the time to compare among treatments (Figure 1). The milk proteins had varying effects on the frequency of fully propagating synchronous contractions (Figure 2) and nonpropagating contractions localized to the proximal colon (Figure 3). We detected no treatment effects on contractile amplitude for either propagating $(P=0.961)$ or nonpropagating contractions $(P=0.076)$.

\section{CPH Decreased the Frequency of Propagating Synchronous Contractions}

Application of $\mathrm{CPH}$ to colonic tissue decreased motility by reducing the frequency of propagating synchronous contractions compared with the pretreatment control (Figure 2). Concomitantly, $\mathrm{CPH}$ decreased the frequency of nonsynchronous contractions in the proximal colon (Figure 3). These inhibitory effects of $\mathrm{CPH}$ on contractile frequency persisted for at least $30 \mathrm{~min}$ after washout.

\section{Whey Proteins Did Not Alter Synchronous Contractile Activity}

Application of either WPC or WPH to the colonic tissue resulted in no change in contractile activity over $60 \mathrm{~min}$. However, both whey products decreased the frequency of nonsynchronous contractions in the proximal colon (Figures 2 and 3).

\section{MPH Increased the Frequency of Propagating Synchronous Contractions}

Application of MPH to the colonic tissue increased motility by increasing the frequency of propagating synchronous contractions compared with the pretreatment control (Figure 2), and this effect persisted after washout. This finding was consistent with the enhanced fecal output associated with MPH compared with $\mathrm{CPH}$ in vivo (Dalziel et al., 2017b). However, MPH did not alter the frequency of nonsynchronous contractions in the proximal colon.

\section{Ratio of Nonsynchronous to Synchronous Contractions}

The ratio of nonsynchronous to synchronous contractile activity gives a measure of the extent to which the proportion of contractions in the proximal colon are isolated events compared with those that propa- gate along the length of the colon in a synchronous manner. The contractions that propagate over longer lengths of colon may contribute more to the propulsion of contents. A higher proportion of these contractions is reflected by a lower ratio; the ratio of nonsynchronous to synchronous contractions averaged 6.5:1 across all pretreatment controls and was increased to 11.7:1 by $\mathrm{CPH}$, because synchronous propagation frequency decreased to a greater extent than for nonsynchronous contractions. The WPC and WPH showed little difference in the ratio of nonsynchronous to synchronous contractions (5.7:1 and 6.1:1, respectively), whereas the ratio was reduced to $3.1: 1$ by MPH.

\section{Comparison with Effects on In Vivo Transit of Solid Matter}

The main finding of this study was a decrease in the frequency of synchronized colonic contractions with $\mathrm{CPH}$ and an increase with MPH (Table 2), consistent with the in vivo actions of these proteins on the movement of solid contents and fecal output previously reported in rats (Dalziel et al., 2017b). From our findings, the effect of the milk proteins on colonic motility may be ranked from increased to decreased frequency of synchronous contractions as $\mathrm{MPH} \geq \mathrm{WPH}=\mathrm{WPC} \geq$ $\mathrm{CPH}$. Previous work showed that in rats fed these milk proteins as their sole protein source for $3 \mathrm{wk}$, the effects on the GI transit of solid contents tracked using metallic beads and X-ray imaging from the stomach at $9 \mathrm{~h}$ (small intestine) for most rapid to slowest was ( $\mathrm{MPH}=$ $\mathrm{WPH}) \geq \mathrm{CPH} \geq \mathrm{WPC}$ (Dalziel et al., 2017b). In that study, no difference was reported at $12 \mathrm{~h}$ when most beads were moving into the cecum and large intestine. However, fecal output as a measure, would better reflect the more distal GI tract location where colonic transit occurs, and in this study ranked from high to low was $\mathrm{MPH}=\mathrm{WPH} \geq \mathrm{WPC} \geq \mathrm{CPH}$. Although fecal output reported for $\mathrm{CPH}$ was less than that for MPH and $\mathrm{WPH}$, the ability of prucalopride (5- $\mathrm{HT}_{4}$ agonist) to enhance it suggests that $\mathrm{CPH}$ had an inhibitory action (Dalziel et al., 2017b). This was consistent with the inhibitory effects we detected in the isolated colon. Given the likely presence of $\beta$-casomorphin peptides in $\mathrm{CPH}$, we speculate that its inhibitory effect on propagating synchronous contractions likely involves the activation of enteric nervous system opioid receptors (Daniel et al., 1990; Dalziel et al., 2014). As well, $75 \%$ of $\mathrm{CPH}$ peptide content is less than $5 \mathrm{kDa}$, a relatively high proportion of potentially bioactive peptides (Table 1 ).

We confirmed ex vivo the $\mathrm{CPH}$ and $\mathrm{MPH}$ actions that had been previously determined in vivo, but this was not the case for WPH. Although WPH had an inhibitory effect on nonpropagating contractions, it had 
A Control

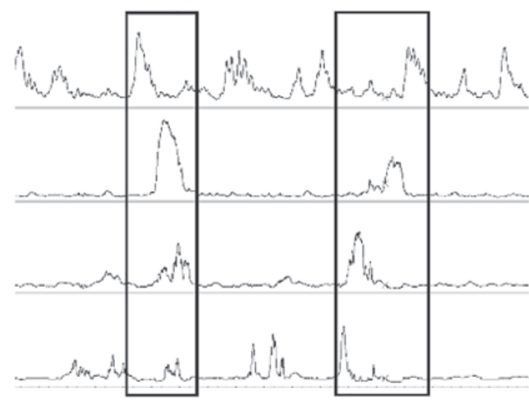

B Control

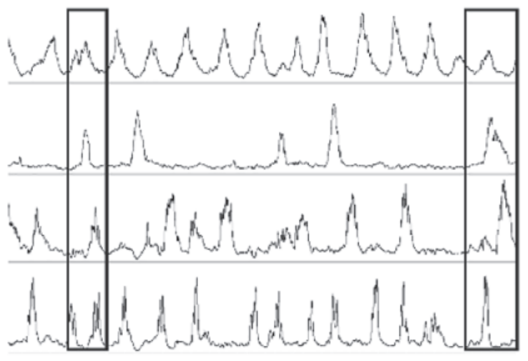

C Control

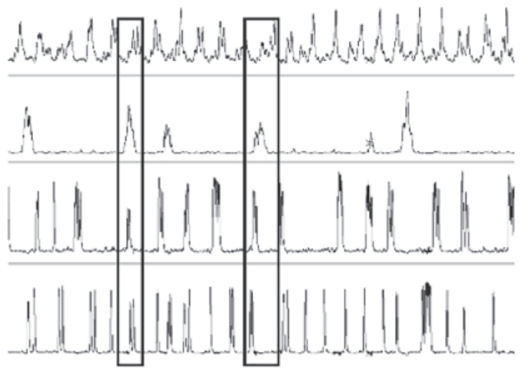

$\mathrm{CPH}$

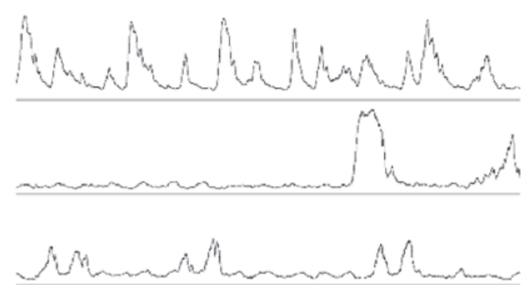

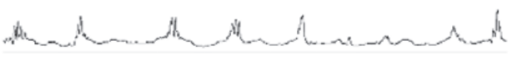

WPC

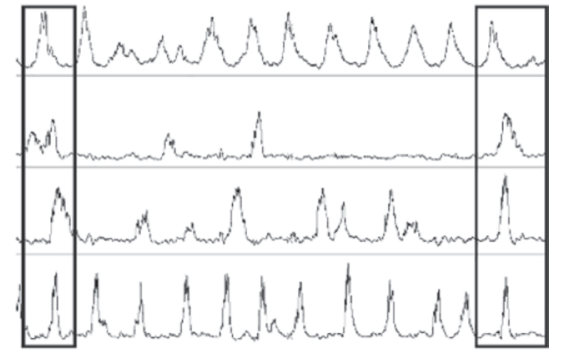

WPH

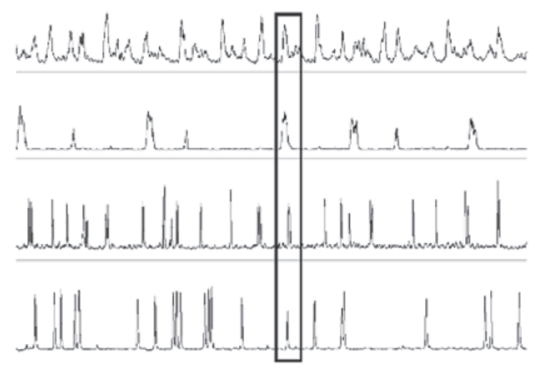

D Control

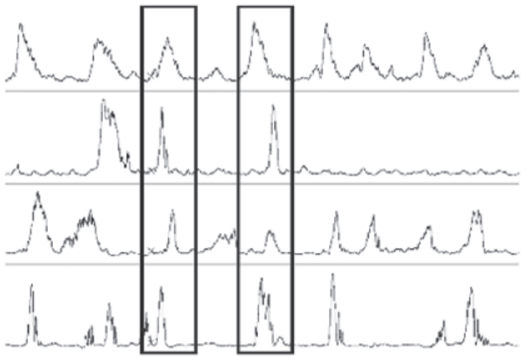

$\mathrm{MPH}$

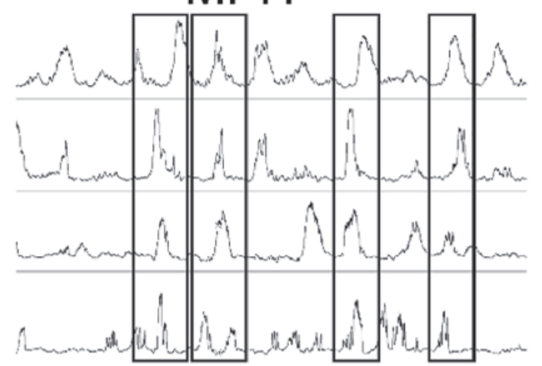

$20 \mathrm{~g}$

\section{$2 \min$}

Figure 1. Actions of dairy proteins on muscle contractile patterns in the isolated rat large intestine. Representative examples show a 10-min recording of muscle contraction from each of the 4 recording locations for the pretreatment control (30 min) and over 30 to 60 min of treatment with $(\mathrm{A})$ casein protein hydrolysate $(\mathrm{CPH}) ;(\mathrm{B})$ whey protein concentrate (WPC); (C) whey protein hydrolysate (WPH); and (D) milk protein hydrolysate (MPH; 60:40 whey:casein hydrolyzed blend). The windows show synchronous contractions that overlap in time. (20 g is the scale for muscle contractile tension.) 
Table 2. Comparison of ex vivo gastrointestinal motility and in vivo movement of solid contents ${ }^{1}$

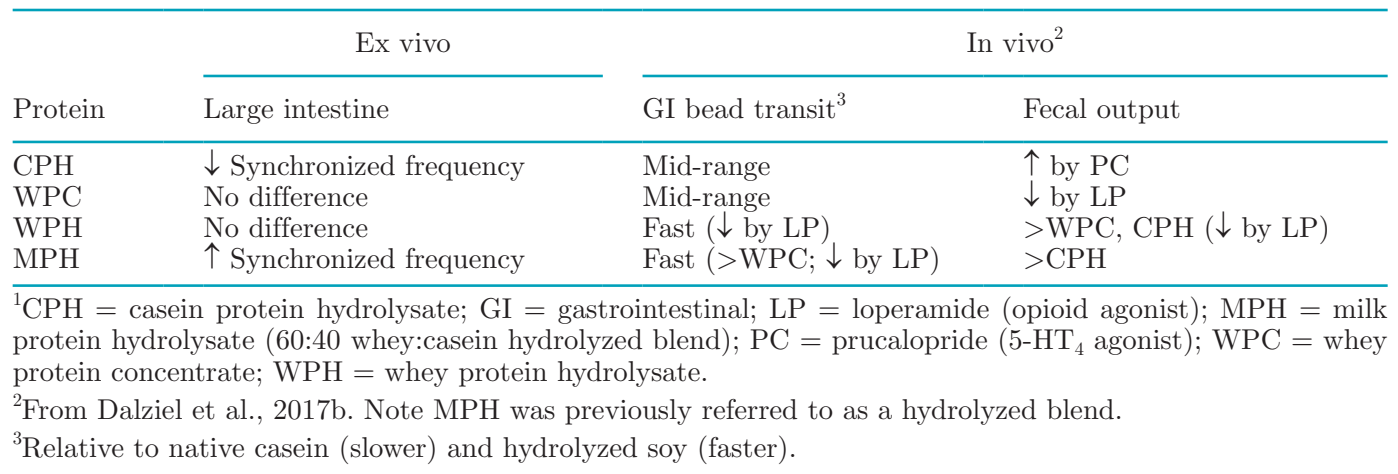

only a minor effect on the overall contractile motility pattern. Reduced fecal output for WPC and WPH with loperamide (an opioid agonist; Dalziel et al., 2017b) suggests that these proteins do not contain significant motility-inhibiting components. In this regard, the midrange ranking of WPC with respect to GI transit and fecal output was consistent with its lack of inhibitory effect ex vivo. The lack of effect of WPH ex vivo was not consistent with its rapid GI transit action in vivo, which, being similar to that for MPH, would also be expected to increase ex vivo. However, this lack of effect did match with the higher fecal output for WPH

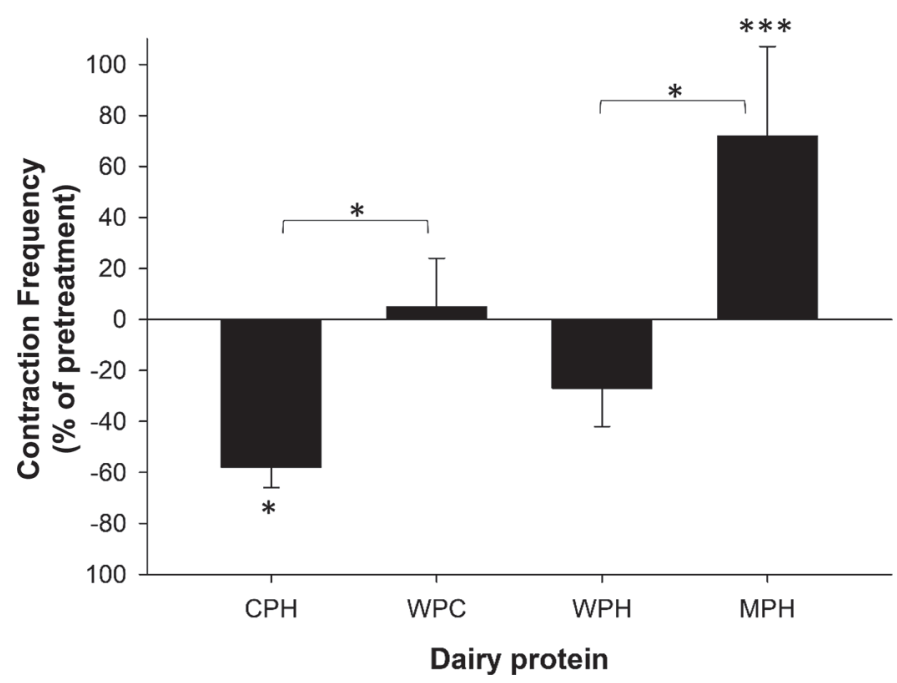

Figure 2. Summary graph of treatment effects on frequency of synchronous contractions in the isolated large intestine. Data are shown as percent change from the pretreatment control for casein protein hydrolysate $(\mathrm{CPH} ; \mathrm{n}=6)$, whey protein concentrate (WPC; $\mathrm{n}=6$ ), whey protein hydrolysate ( $\mathrm{WPH} ; \mathrm{n}=5)$, and milk protein hydrolysate (MPH; 60:40 whey:casein hydrolyzed blend; $\mathrm{n}=5$ ). Synchronous contractions between the proximal colon and rectum that were temporally coordinated in anterograde, mid- or retrograde direction were measured during a 30-min control recording and compared with those recorded over 30 to $60 \mathrm{~min}$ of exposure to treatments. Asterisks indicate statistical significance $\left({ }^{*} P<0.05 ;{ }^{* * *} P<0.001\right)$. Data show mean \pm SEM. relative to CPH (Dalziel et al., 2017b). The discrepancy between WPH action in vivo and minimal effect ex vivo suggests that additional factors occur in vivo to facilitate the timely GI transit of contents. Because WPH is only $7 \%$ hydrolyzed compared with MPH (12-17\% hydrolyzed), it is likely that more and smaller bioactive peptides are released during digestion of WPH that may be absorbed and act on colonic tissue via uptake from the arterial bloodstream. It is also possible that intact neural pathways are required. Alternatively, the microbiota may be influential for WPH in eliciting its modulatory effect in vivo via epithelial cells on intrinsic primary afferent neurons. Further studies using either

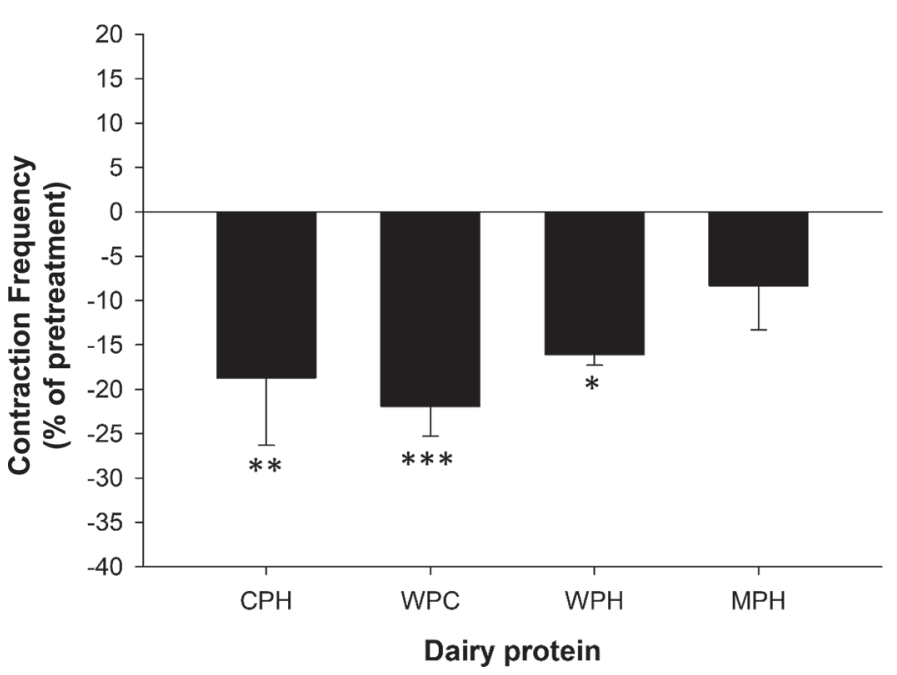

Figure 3. Summary graph of treatment effects on frequency of nonsynchronous contractions in the proximal colon. Data are shown as percent change from the pretreatment control for casein protein hydrolysate $(\mathrm{CPH} ; \mathrm{n}=6)$; whey protein concentrate (WPC; $\mathrm{n}=6$ ); whey protein hydrolysate (WPH; $\mathrm{n}=5$ ); and milk protein hydrolysate (MPH; 60:40 whey:casein hydrolyzed blend; $\mathrm{n}=5$ ). Nonsynchronous contractions that occurred only in the proximal colon without further propagation were measured during a $30 \mathrm{~min}$ control recording and compared with those recorded over 30 to $60 \mathrm{~min}$ of exposure to treatments. Asterisks indicate statistical significance $\left({ }^{*} P<0.05\right.$; ${ }^{* *} P<$ $0.01 ; * * * P<0.001)$. Data show mean \pm SEM. 
digesta or in vitro digested and microbially fermented dairy protein will explore these possibilities.

The direct effect of MPH on colon tissue in the present study was consistent with that reported in infant studies. A partially hydrolyzed 60:40 whey:casein infant formula accelerated the transit of milk and stools compared with a nonhydrolyzed form in preterm infants (Mihatsch et al., 2001). Feeding of partially hydrolyzed infant formula has also been shown to produce more frequent and softer stools and shorten GI transit time compared with standard formula (Mihatsch et al., 2001; Vandenplas et al., 2014).

\section{CONCLUSIONS}

We report a reduction in colonic motility with $\mathrm{CPH}$ compared with WPC, and increased motility with $\mathrm{MPH}$, similar in principle to their known actions on the movement of solid contents and fecal output in previous in vivo studies in rats. The factors involving WPH actions require further investigation in vivo. A direct modulatory action of $\mathrm{CPH}$ and $\mathrm{MPH}$ milk proteins on colon tissue provides evidence that bioactive peptides are present in these hydrolysates before ingestion. This tissue model provides a template for further investigating the mechanisms that underlie altered colonic motility function.

\section{ACKNOWLEDGMENTS}

This research was supported by funding from the Ministry of Business Innovation and Employment, New Zealand (C10X1003), with co-funding from Fonterra Co-operative Group Ltd. and provision of the milk protein ingredients. We thank R. Broadhurst and B. Smith for animal breeding, and H. Gillespie for animal care. J.D. designed the study, analyzed the data, interpreted the results, and wrote the paper; J.P. and K.D. carried out the experiments, C.M. carried out statistical design and analysis; N.S, N.H., and N.R. contributed to study design and critically revised the manuscript. The authors declare no conflict of interest. All authors had complete access to the data that supports the publication. N.W.H is an employee of Fonterra Co-operative Group Ltd.

\section{REFERENCES}

Abd El-Salam, M. H., and S. El-Shibiny. 2017. Preparation, properties, and uses of enzymatic milk protein hydrolysates. Crit. Rev. Food Sci. Nutr. 57:1119-1132.

Bourlieu, C., O. Ménard, K. Bouzerzour, G. Mandalari, A. Macierzanka, A. R. Mackie, and D. Dupont. 2014. Specificity of infant digestive conditions: Some clues for developing relevant in vitro models. Crit. Rev. Food Sci. Nutr. 54:1427-1457.

Boutrou, R., C. Gaudichon, D. Dupont, J. Jardin, G. Airinei, A. Marsset-Baglieri, R. Benamouzig, D. Tomé, and J. Leonil. 2013. Sequential release of milk protein-derived bioactive peptides in the jejunum in healthy humans. Am. J. Clin. Nutr. 97:1314-1323.

Costa, M., K. N. Dodds, L. Wiklendt, N. J. Spencer, S. J. H. Brookes, and P. G. Dinning. 2013. Neurogenic and myogenic motor activity in the colon of the guinea pig, mouse, rabbit, and rat. Am. J. Physiol. Gastrointest. Liver Physiol. 305:G749-G759.

Dalziel, J. E., R. C. Anderson, B. A. Bassett, C. M. Lloyd-West, N. W. Haggarty, and N. C. Roy. 2016. Influence of bovine whey protein concentrate and hydrolysate preparation methods on motility in the isolated rat distal colon. Nutrients 8:e809.

Dalziel, J. E., R. C. Anderson, J. S. Peters, A. T. Lynch, N. J. Spencer, J. Dekker, and N. C. Roy. 2017a. Promotility action of the probiotic Bifidobacterium lactis HN019 extract compared with prucalopride in isolated rat large intestine. Front. Neurosci. 11:20.

Dalziel, J. E., V. Mohan, J. Peters, R. C. Anderson, P. K. Gopal, and N. C. Roy. 2015. The probiotic Escherichia coli Nissle 1917 inhibits propagating colonic contractions in the rat isolated large intestine. Food Funct. 6:257-264.

Dalziel, J. E., N. J. Spencer, K. E. Dunstan, A. T. Lynch, N. W. Haggarty, P. K. Gopal, and N. C. Roy. 2014. An in vitro rat model of colonic motility to determine the effect of $\beta$-casomorphin- 5 on propagating contractions. Food Funct. 5:2768-2774.

Dalziel, J. E., W. Young, C. M. McKenzie, N. W. Haggarty, and N. C. Roy. 2017b. Gastric emptying and gastrointestinal transit compared among native and hydrolyzed whey and casein milk proteins in an aged rat model. Nutrients 9:1351.

Daniel, H., M. Vohwinkel, and G. Rehner. 1990. Effect of casein and $\beta$-casomorphins on gastrointestinal motility in rats. J. Nutr. 120:252-257.

Iwan, M., B. Jarmołowska, K. Bielikowicz, E. Kostyra, H. Kostyra, and M. Kaczmarski. 2008. Transport of $\mu$-opioid receptor agonists and antagonist peptides across Caco-2 monolayer. Peptides $29: 1042-1047$

Jahan-Mihan, A., B. L. Luhovyy, D. E. Khoury, and G. Harvey Anderson. 2011. Dietary proteins as determinants of metabolic and physiologic functions of the gastrointestinal tract. Nutrients 3:574-603.

Jarmołowska, B., M. Teodorowicz, E. Fiedorowicz, E. SienkiewiczSzłapka, M. Matysiewicz, and E. Kostyra. 2013. Glucose and calcium ions may modulate the efficiency of bovine $\beta$-casomorphin- 7 permeability through a monolayer of Caco-2 cells. Peptides 49:5967.

Korhonen, H. 2009. Milk-derived bioactive peptides: From science to applications. J. Funct. Foods 1:177-187.

Mason, S. 1962. Some aspects of gastric function in the newborn. Arch. Dis. Child. 37:387-391.

McGregor, R. A., and S. D. Poppitt. 2013. Milk protein for improved metabolic health: A review of the evidence. Nutr. Metab. (Lond.) 10:46.

Mihatsch, W. A., J. Högel, and F. Pohlandt. 2001. Hydrolysed protein accelerates the gastrointestinal transport of formula in preterm infants. Acta Paediatr. 90:196-198.

Schmidt, R., K. Neubert, A. Barth, C. Liebmann, M. Schnittler, N. N. Chung, and P. W. Schiller. 1991. Structure-activity relationships of cyclic $\beta$-casomorphin-5 analogues. Peptides 12:1175-1180.

Spencer, N. J., P. G. Dinning, S. J. Brookes, and M. Costa. 2016. Insights into the mechanisms underlying colonic motor patterns. J. Physiol. 594:4099-4116.

Vandenplas, Y., S. Cruchet, C. Faure, H. C. Lee, C. Di Lorenzo, A. Staiano, X. Chundi, M. M. Aw, P. Gutiérrez-Castrellõn, A. Asery, J. Spolidoro, R. G. Heine, M. Miqdady, M. E. Arancibia, and P. Alarcõn. 2014. When should we use partially hydrolysed formulae for frequent gastrointestinal symptoms and allergy prevention? Acta Paediatr. 103:689-695. 